\title{
Surgical intervention for capsule endoscope retained at ileal stricture
}

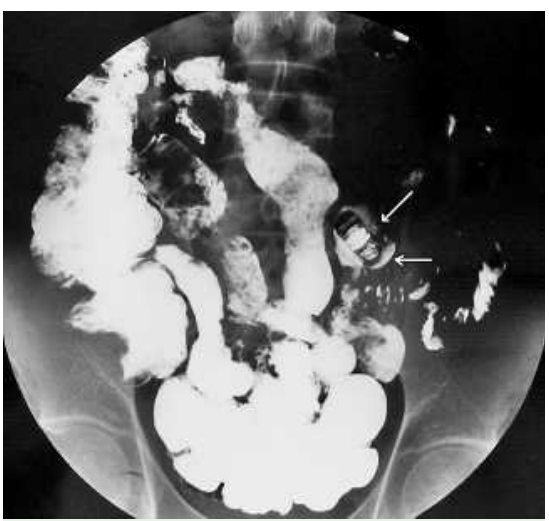

Fig. 1 Capsule endoscope impacted at ileal stenosis.

Capsule endoscopy is an invaluable, safe examination for the small bowel [1]. We report a case of operation for a capsule endoscope retained at an ileal stricture in a patient with multiple ileal strictures. A 37-year-old man presented with a 3year history of abdominal pain, gastrointestinal bleeding, and intermittent incomplete ileus. He underwent comprehensive investigations including gastroscopy, colonoscopy, and computed tomography (CT) of the abdomen at a tertiary medical center elsewhere, and the findings were unremarkable. Capsule endoscopy was carried out to investigate the small bowel for any potential cause of the symptoms. After ingestion of the capsule, the patient was found to have multiple small-bowel diverticulosis, and he did not see the capsule pass in the stool. Three weeks later he developed intermittent attacks of abdominal pain. Barium examination of the small bowel revealed the capsule endoscope impacted at an ileal stenosis ( $\bullet$ Fig. 1). The patient was referred to our hospital for further evaluation. We inserted a double-balloon enteroscope anally and found the capsule endoscopy trapped on the oral side of a severe ileal stenosis. Owing to the severe stenosis we failed to retrieve the capsule endoscope. Four days later, the patient's abdominal symptoms worsened and Xray plain film revealed incomplete ileus and a metallic density within it ( $\bullet$ Fig. 2). After consultation with a senior general surgeon, the patient was scheduled to undergo operative interven-

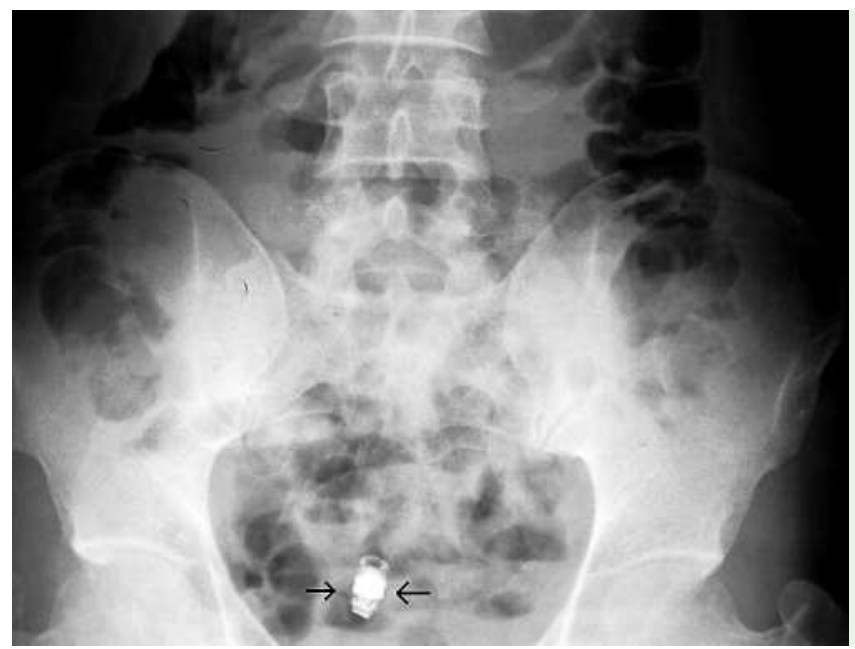

Fig. 2 Retained capsule as seen in abdominal plain X-ray film.

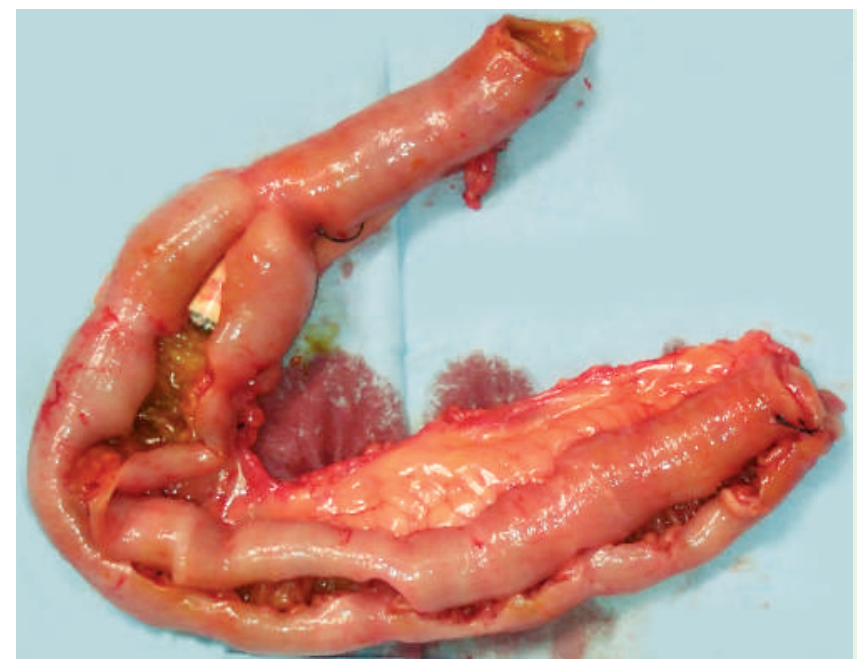

Fig. 3 Capsule endoscope retained at ileal stenosis confirmed by surgery.

tion. The operation went smoothly and a diagnosis of Crohn's disease was confirmed ( $\bullet$ Fig. 3).

Tanaka et al. reported successful retrieval of a capsule endoscope retained at an ileal stenosis in Crohn's disease using double-balloon endoscopy [2], confirming that double-balloon endoscopy may be the best method by which to retrieve a retained capsule endoscope because it is able to reach the whole gut. Thus, if a capsule endoscope is impacted, it may be retrieved safely by endoscopy; but because endoscopy is unable to deal with irreversible intestinal stenosis, when concomitant ileus is present, surgery should be considered.

Endoscopy_UCTN_Code_CPL_1AI_2AB
Y. Bai ${ }^{1}$, J. Gao ${ }^{1}$, B. Song ${ }^{2}$, Y. Q. Zhou ${ }^{2}$, D. W. Zou ${ }^{1}$, Z. S. Li ${ }^{1}$

Department of Gastroenterology, Changhai Hospital, Second Military Medical University, Shanghai, China

2 Third Department of General Surgery, Changhai Hospital, Second Military Medical University, Shanghai, China 


\section{References}

1 Rey JF, Ladas S, Alhassani A et al. European Society of Gastrointestinal Endoscopy (ESGE). Video capsule endoscopy: update to guidelines (May 2006). Endoscopy 2006; 38: 1047 - 1053

2 Tanaka S, Mitsui K, Shirakawa K et al. Successful retrieval of video capsule endoscopy retained at ileal stenosis of Crohn's disease using double-balloon endoscopy. J Gastroenterol Hepatol 2006; 21: $922-923$
Bibliography

DOI $10.1055 / \mathrm{s}-2007-966608$

Endoscopy 2007; 39: E268 -E269

(c) Georg Thieme Verlag KG Stuttgart · New York .

ISSN 0013-726X

\section{Corresponding author}

\section{Z. S. Li, MD PhD}

Department of Gastroenterology

Changhai Hospital

Second Military Medical University

174 Changhai Road

Shanghai

China

Fax: +86-21-55621735

li.zhaoshen@hotmail.com 